\title{
Assisted Reproductive Technology in Nigeria: Flawed or Favored?
}

\author{
Tolulope Monisola Ola
}

\begin{abstract}
Infertility is the inability or failure to conceive or impregnate after at least one year of unprotected coitus and most of those who suffer from infertility live in developing countries. Its management is supposed to be an important component of reproductive health services. In Nigeria, when infertility occurs, couples seek various treatments, including assisted reproductive technologies. Assisted Reproductive Technologies (ART) is a novel technology which raises a number of challenges with which society has to cope. This review paper describes the issues, goals, prospects and problems of ART in Nigeria. Crucial issues such as the methods of ART available, the cost of ART, statistics of practice and results of ART are discussed. The role of the Government and some non-governmental organizations is outlined. The paper stresses the role of research in solving these problems and finally suggests preventive strategies which may be adopted in other to reduce the incidences of infertility in Nigeria.
\end{abstract}

Index Terms_-ART, infertility.

\section{INTRODUCTION}

Infertility is a major public health problem with devastating consequences. Throughout much of sub-Saharan Africa, several reports [1] [2] indicate that infertility extends beyond the loss of human potential and unrealized self. It is a cause of physical, social and verbal abuse of couples affected. The quest of infertile couples to resolve the problem of infertility has resulted in the patronage of various treatment outlets with different treatment options. A range of medical treatment options exist for infertility, which fall into two broad categories: Low-tech treatments, which accounts for more than 95 per cent of modern, medical infertility treatments. They are those that do not involve the retrieval of oocytes or fertilization outside the body, which often include the use of fertility drugs to stimulate superovulation, the development and release of more than one egg per ovulatory cycle, and intrauterine insemination, a process by which sperm are placed inside a woman's cervix to facilitate fertilization and pregnancy; and high-tech treatments, also called Assisted Reproductive Technologies (ARTs) [3].

Assisted Reproductive Technologies (ARTs) refers to all treatments or procedures that include the in vitro (IVF) handling of human oocytes and sperm or embryos for the purpose of establishing a pregnancy. This includes, but is not limited to, in vitro fertilization and trans cervical embryo transfer, gamete intra fallopian transfer, zygote intra

Manuscript received June 1, 2012; revised July 4, 2012.

T. M. Ola is with the Department of Sociology, Faculty of the Social Sciences, Ekiti State University, Nigeria (e-mail:tolulopeola2003@yahoo.co.uk; tel: +234 8139389 466). fallopian transfer, tubal embryo transfer, gamete and embryo cryopreservation, oocyte and embryo donation and gestational surrogacy. ART does not include assisted insemination (artificial insemination) using sperm from either a woman's partner or sperm donor [4].

Since the first 'test-tube baby' Louise Brown was born in Britain in 1978, more than a million children have been born through assisted reproductive technology (ART). The original IVF technology involved mixing eggs and sperm in a laboratory dish (in vitro fertilization or IVF) and then implanting the resulting embryos (embryo transfer or ET) into the womb or uterus. The technique was developed to help women with blocked fallopian tubes and who, apart from their blocked tubes have no additional fertility problems. Since early studies suggested that the new technology was without additional risk to mother and baby, IVF soon became widely accepted and modified developments and the treatment of complex types of infertility became available [5].

Since the prevalence of infertility in Nigeria is high compared to most other African countries for which data are available [6], there is a potentially large demand for ART services in Nigeria. This paper therefore examines the issues, goals, prospects and problems of ART in Nigeria.

\section{ART IN NIGERIA}

Infertility is viewed as an enormous problem by women everywhere but their responses to the problem varies worldwide. Due to the social and cultural factors attached to motherhood in Nigeria, women go through various health-seeking or fertility-seeking modes due to internal and external pressures.

Over the last two decades, Assisted Reproductive Technologies (ART) that assist reproduction increasing the chances of conception has rapidly increased. The number of countries now practicing ART has multiplied many times and it is available throughout Asia, the Middle East, South America, and parts of Africa.

Table I below shows that virtually all forms of ART are now available in Nigeria and other sub regions namely: artificial insemination by husband (AIH), donor insemination (DI), in vitro fertilization (IVF), gamete intrafallopian transfer (GIFT), zygote intrafallopian transfer (ZIFT), intracytoplasmic sperm injection (ICSI), embryo freezing and embryo donation, surrogate motherhood. The most widely practiced methods in sub Saharan Africa countries are AIH, DI, and IVF [7], [8], [9], [10]. 


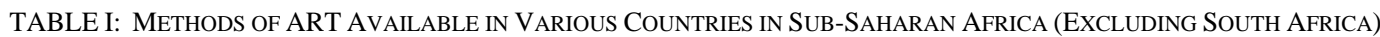

\begin{tabular}{|l|l|l|l|l|l|l|l|l|}
\hline Country & $\begin{array}{l}\text { AIH } \\
\text { /DI }\end{array}$ & IVF & $\begin{array}{l}\text { GIF } \\
\text { T/ZI } \\
\text { FT }\end{array}$ & $\begin{array}{l}\text { Oocy } \\
\text { te } \\
\text { donat } \\
\text { ion }\end{array}$ & $\begin{array}{l}\text { Egg } \\
\text { sharing }\end{array}$ & $\begin{array}{l}\text { Embryo } \\
\text { freezing }\end{array}$ & TESA & ICSI \\
\hline Nigeria & Yes & Yes & Yes & Yes & Yes & Yes & Yes & Yes \\
\hline Ghana & Yes & Yes & N/A & N/A & N/A & Yes & Yes & Yes \\
\hline $\begin{array}{l}\text { Cameroo } \\
\text { n }\end{array}$ & Yes & Yes & N/A & N/A & N/A & N/A & N/A & N/A \\
\hline Togo & Yes & Yes & N/A & No & N/A & N/A & N/A & N/A \\
\hline Senegal & Yes & Yes & No & N/A & N/A & N/A & N/A & N/A \\
\hline $\begin{array}{l}\text { Benin } \\
\text { Republic }\end{array}$ & Yes & No & N/A & No & No & No & No & No \\
\hline $\begin{array}{l}\text { Zimbabw } \\
\text { e }\end{array}$ & Yes & Yes & N/A & Yes & Yes & Yes & Yes & Yes \\
\hline Kenya & Yes & Yes & N/A & No & No & No & No & No \\
\hline $\begin{array}{l}\text { Sierra } \\
\text { Leone }\end{array}$ & Yes & Yes & N/A & No & No & No & No & No \\
\hline
\end{tabular}

Source: Giwa-Osagie, 2002N/A: information not available

The Lagos University Teaching Hospital team of GiwaOsagie, Ashiru and Abisogun produced documented pregnancies through IVF in 1984, 1986 [11] , and a live birth in 1989. The first baby born in West Africa as a result of IVF was delivered at the Lagos University Teaching Hospital in 1989. By 2001, there were eight assisted conception centres carrying out IVF in sub-Saharan Africa, as well as numerous other centres offering artificial insemination [12].

There were successes recorded from IVF in the whole of West, East and Central Africa which shows that assisted reproductive technologies are feasible and successful in low resource settings where staffs are trained and equipment are available [13]. Ajayi et al [14] reported two cases of successful ICSI from a private IVF clinic in Lagos, Nigeria. In one case, a man had no sperm in his semen, so sperm were extracted from his testes. ICSI and transfer of the resulting embryo into the uterus of his 38-year-old wife resulted in the birth of a healthy baby boy. In the other instance, a 31-year-old woman who had tubal infertility and whose husband had low sperm counts delivered twins after ICSI was performed. Table 2 shows the statistics of ART activities in some established centres in Nigeria.

TABLE II: ART ACTIVITIES IN ESTABLISHED UNITS IN NIGERIA

\begin{tabular}{|l|l|l|l|l|l|l|}
\hline & $\begin{array}{l}\text { AIH/ } \\
\text { DI }\end{array}$ & IVF & $\begin{array}{l}\text { ZIFT } \\
\text { /GIF } \\
\text { T }\end{array}$ & $\begin{array}{l}\text { Embryo } \\
\text { freezing }\end{array}$ & $\begin{array}{l}\text { Oocyte } \\
\text { donation }\end{array}$ & ICSI \\
\hline Lagos & Yes & Yes & Yes & Yes & Yes & No \\
\hline $\begin{array}{l}\text { Advanced } \\
\text { Clinic }\end{array}$ & Yes & Yes & No & No & Yes & No \\
\hline $\begin{array}{l}\text { Providence } \\
\text { Hospital }\end{array}$ & Yes & Yes & No & No & Yes & Yes \\
\hline Clinic & Yes & Yes & Yes & Yes & Yes & yes \\
\hline Abuja & $\begin{array}{l}\text { Nisa-Premi } \\
\text { er Hospital }\end{array}$ & Yese & & & \\
\hline
\end{tabular}

Source: Modified and adapted for use from Giwa-Osagie, 2002.

However, with all these advances, there are scientific, health services, professional and social challenges which are still to be faced. One challenge that cuts across all others is how to make ART more widely available and affordable for all who need it in developing countries ${ }^{(15)}$. In addition, appropriate guidelines and regulations in most developing countries are lacking which is a serious drawback in efforts to improve the quality of the services provided.

\section{Challenges to ART in Nigeria}

According to [15], there are important scientific challenges still to be faced in the field of assisted reproduction in spite of the tremendous scientific progress that has been made so far. This includes improving success rates which have been fairly constant, at around $25 \%$ live births per cycle, until age of 34 years, when there is steep decline [16].

In the process of improving success rates, it was opined that there is need to increase the chances for implantation through transfer of more than one embryo to the uterus which invariably increases the risk of multiple gestations [15]. A world collaborative report on in vitro fertilization (IVF) recorded a multiple birth rate of $29 \%$, the majority of which are twins [17]. This issue of multiple gestations can lead to the shortage of gametes and also an increased risk of perinatal and infant morbidity and mortality.

Discussions of the new reproductive technologies bring forth multiple themes and cultural values, having to do with human rights and morality, gender roles, expectations about human developments and life transitions, the cultural construction of the body, the self and national identity [18], [19]. Cultural and religious values and beliefs, as well as the health care infrastructure and economic development, influence the level of services provided in any one country. In most cases, when assisted reproductive technologies are available, they are provided by the private sector, making infertility services accessible only to the middle and upper classes [14]. In addition, the centers and physicians providing assisted reproductive technologies are often located in large cities, making it too time consuming and expensive for couples to access from more remote areas. Access to ART is limited by cost. It is not easily affordable because it is an 
expensive procedure. In Nigeria, a cycle of IVF costs about US\$ 2000 - US\$ 2700 (250,000 to 350,000 Naira) [10]. Therefore, for an average Nigerian, ART is not currently affordable and easily accessible since it is not done in the public sector because of lack of funds except in the private sector.

There are numerous ethical and social questions associated with the access-to-services in the treatment for infertility through assisted reproduction. One of the most troubling is the process of selection of patients in terms of their age, marital status sexual identity and medical conditions (such as $\mathrm{HIV}$, infectious diseases, risk of harm for the treated or for the offspring). There are other ethical dilemmas regarding providing services in cases of alcohol consumption, the use of illegal drugs or social nonconformity [20]. ART is an issue with many facts that contribute to the ethical arguments surrounding it. It tends to give another meaning to parenting since it involves many people contributing to the procedure. This is done so as to maximize the chances of a successful pregnancy. In many countries, questions of parentage and legitimacy of children born as a result of ART involving a donor are unresolved. There are objections to this which are often based on preconceived ideas of what should constitute a family unit [12].

There is the issue of the commodification of people which is a cloudier sub issue for ART since it could be argued in two ways. First, from the very beginning, when a woman decides to donate her eggs or a man his sperm, some people can argue that this is buying and selling of human beings or at the very least, the makeup of humans. The final factor that has had a major impact on the ability to perform many of the new reproductive technologies is the rapid technological advances that have occurred in the past two decades.

Despite these challenges, many developing countries have seen the introduction of new reproductive technologies through a global transfer of technology [19]. The expected roles of Government should include health financing of ARTs and Non Governmental Organizations (NGOs) should work to safeguard and expand the human rights, equality and preventive health of men and women. In addition, health providers and program managers can help clients safeguard their health by providing education on the biological causes of infertility and the links between untreated or improperly treated STIs and infertility. For example, an intervention in Nigeria utilized peer educators, school-based health clubs, and provider training to increase youth knowledge of STIs and STI treatment-seeking behavior [21]. It has been recommended that public health policy should invest in preventing the causes of infertility and leave the establishment of new assisted reproductive technologies to the private sector since it is unlikely to be cost-effective in the public sector [21]. Researchers advocate for governments to invest in more quality-control and regulatory policies to help prevent exploitation of patients in low-resource settings [22]. By offering infertility education and services, family planning programs in developing countries can build a positive image for their program and for family planning, even as they meet a widespread health need [23]. Family planning programs also can help prevent infertility by reducing STI and PID risks among their clientele [24]. In an effort to make much needed assisted reproductive technologies to developing countries accessible and affordable, some researchers are looking at public-private partnerships. These partnerships can bring technical expertise, research, equipment, and supplies to low-resource settings. At the same time, public-private partnerships can offer services at lower costs that are more realistic in developing countries. In addition, public-private partnerships can help influence the establishment of standards, regulations, and policies to safeguard the health of couples undergoing treatment [25], [10].

\section{SUMMARY, CONCLUSION AND RECOMMENDATIONS}

Assisted Reproductive Technologies (ARTs) embraces all infertility treatments and it is a dynamic and rapidly developing field of medical practice in Nigeria especially in the private health sector. In spite of this, the techniques are still not available to majority of infertile couples with irreversible forms of infertility in Nigeria because it is unaffordable.

\section{CONCLUSION}

There are no States legislations, researchers that have documented the risks posed by ARTs, and the ethical, moral, legal and social issues raised by ARTs are unresolved. This is a major flaw to ARTs in Nigeria.

\section{RECOMMENDATIONS}

In view of this, Government should make the issue of legalization, affordability, accessibility, management guidelines, licensing, and reporting systems a priority on their agenda.

\section{REFERENCES}

[1] T. Gerrits, "Social and cultural aspects of infertility in Mozambique," Patient Educ. Couns., vol.31, pp.39-48, 1997.

[2] N. Papreen, A. Sharma, K. Sabina, L. Begum, S. K. Ahsan, and A. H. Baqui, Living with infertility: Experiences among urban slum populations in Bangladesh. Reproductive Health Matters, vol.8, pp.33-44, 2000.

[3] A. Fidler and J. Bernstein, Infertility: From a personal to a public health problem. Public Health Rep. vol. 114, pp. 494-511, 1999. [Online]. Available: http://www.ncbi.nlm.nih.gov/pmc/articles/PMC1308532/

[4] E. Vayena, P. J. Rowe, and P. D. Griffin, "Current practices and controversies in assisted reproduction," Report of a Meeting on Medical, Ethical and Social Aspects of Assisted Reproduction. WHO, Geneva, Switzerland, 2001

[5] D. R. J. A.Macer, Cross-Cultural Introduction to Bioethics. Eubios Ethics Institute, New Zealand, 2006.

[6] U. Larsen, Differentials in infertility in Cameroon and Nigeria. Population Stud., [Online]. vol. 49, pp.329-346, 1995. [Online]. Available: http://www.jstor.org/pss/2175160.

[7] O. F. G-Osagie, C. Nwokoro, and D. Ogunyemi, Donor insemination in Lagos. Clinical Reproductive Fertility. vol.3, pp.305-310, 1985.

[8] A. O. Ashiru, A. O. Abisogun, and O. F. Giwa-Osagie, Fertilisation of pre-ovulatory human eggs and development $<\mathrm{i}>\mathrm{in}$ vitro $<\mathrm{i}>$ in Lagos. Proceedings of the Endocrine Society, $6^{\text {th }}$ Annual Meeting, June 19-21, Baltimore, USA. pp: 359-359, 1985.

[9] O. F. Giwa-Osagie, O. Ashiru, and A. Sanyaolu, Human acolyte recovery for in vitro fertilisation. The use of cervical mucus and plasma 
oestradiol as indices of follicular development. West Afr. J. Med., vol.7, pp.136-139, 1988.

[10] O. F. Giwa-Osagie, "ART in developing countries with a particular reference to sub-Saharan Africa," In: Current Practices and Controversies in Assisted Reproduction: Report of a WHO Meeting, Vayena, E., P. J. Rowe and P.D. Griffin (Eds.). World Health Organization, Geneva, 2002.

[11] O. F. Giwa-Osagie, Clinical profile, assessment for IVF and the outcome of IVF in Lagos, presented at the 12th World Congress of Fertility and Sterility, pp. 737, 1986.

[12] P. Butler, "Assisted reproduction in developing countries: Facing up to the issues,” Reproductive Health Res., vol.63, pp.1-8., 2003.

[13] A. K. Kibwana, Assisted reproductive technology (ART): experience, current and future status. Presented at the $5^{\text {th }}$ international scientific conference of the East, Central and Southern African Association of Obstetrical and Gynecological Societies, Mombasa Kenya February pp.23-27, 2003

[14] R. A. Ajayi, J. H. Parsons. and V. N. Bolton, Live births after intracytoplasmic sperm injection in the management of oligospermia and azoospermia in Nigeria. Afr. J. Reprod. Health, vol.7, pp. 121-124. [Online]. Available: http://www.jstor.org/pss/3583352.

[15] M. F. Fathalla, "Current challenges in assisted reproduction," In: Current Practices and Controversies in Assisted Reproduction, Report of a WHO Meeting, Vayena, E., P. J. Rowe and P.D. Griffin (Eds.). World Health Organization, Geneva, 2002.

[16] Society for Assisted Reproductive Technology and American Society for Reproductive Medicine. Assisted Reproductive Technology in the United States and Canada: 1995 Results generated from the American Society for Reproductive Medicine/Society for Assisted Reproductive Technology Registry. Fertil. Steril. vol.69. pp.389-398, 1998.

[17] I. D. Cooke and K. J. H. Lim, Implantation. In: The Year Book of Obstetrics and Gynaecology, O’Brien, P.M.S. (Ed.). RCOG Press, London, pp. 206-222, 2000.

[18] F. Ginsburg and R. Rapp, "Introduction: Conceiving the new world order," In Conceiving the New World Order: The Global Politics of Reproduction, Ginsburg, F. and R. Rapp (Eds.). University of California Press, Berkeley, pp.1-19, 1995.

[19] F. V. Balen and M. C. Inhorn, "Introduction: Interpreting infertility: A view from the social sciences," In Infertility around the Globe: New Thinking on Childlessness, Gender and Reproductive Technologies,
Inhorn, M.C. and F. van Balen, (Eds.). University of California Press, Berkeley, pp.3-23, 2002

[20] J. E. Stern, C. Cramer, A. Garrod, and R. Green, “Access to services at assisted reproductive technology clinics: A survey of policies and practices,” Am. J. Obstetric Gynecol., vol.184, pp.591-597.

[21] F. E. Okonofua, New reproductive technologies and infertility treatment in Africa. Afr. J. Reprod. Health. (2003). vol.7, pp.7-11., 2003. [Online]. Available: http://www.jstor.org/pss/3583339

[22] H. V. Zandvoort, K. de Koning, and T. Gerrits, Viewpoint: Medical infertility care in low income countries: The case for concern in policy and practice. Trop. Med. Int. Health, vol.6, pp.563-569, 2001. [Online]. Available:

http://onlinelibrary.wiley.com/doi/10.1046/j.1365-3156.2001.00756.x /pdf:

[23] A. J. Singh, "Support for infertile couples," World Health Forum, vol.17, pp.176-177., 1996.

[24] CDC. Infertility. In Family Planning: Methods and Practice in Africa, Hatcher, R.A., (Ed.). Center for Disease Control and Prevention, Atlanta, Georgia. 2000.

[25] A. S. Daar and Z. Merali, "Infertility and social suffering: The case of ART in developing countries,” In: Vayena, E. Rowe, P. J., and Griffin, P.D., eds. Current Practices and Controversies in Assisted Reproduction: report of a WHO meeting. Geneva: WHO, 2002.

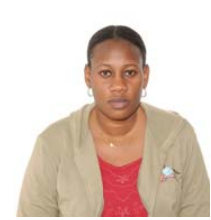

Tolulope Monisola Ola has a BSc in Demography and Social Statistics, an MSc in Medical Sociology and $\mathrm{PhD}$ in Population Studies. She co-founded the Sound Health Development Initiative, which is an NGO with a focus on gender issues in Ekiti State, Nigeria. She also lectures at the Ekiti State University, Ado-Ekiti, Nigeria. Her research interests include a dolescent sexuality, fertility, reproductive and sexual health/rights, Women and Child trafficking, Child abuse and gender, and she conducts research and undertakes advocacy and intervention work on issues related to sexuality and sexual rights. She has acquired an understanding of complex sexualities, as well as of the constrained contexts in which many women and men exercise their sexual rights through her research, which enables her intervention programs to meet their goals. She has participated in sexuality trainings, conferences, summer institutes and internships at the national, regional and international levels. She is a member of so many Professional Associations. She is the Treasurer of Union for Africa Population Studies. 